\title{
Linking Subjects in the Curriculum of Mechanical/Automobile Engineering
}

\author{
Avinash Shaligram ${ }^{1}$ Amey Marathe ${ }^{2}$ \\ ${ }^{1,2}$ Department of Mechanical and Automobile Engineering \\ Pillai Institute of Information Technology, Engineering, Media Studies and Research, \\ Dr K M Vasudevan Pillai Campus, \\ Sector 16, New Panvel - 410 206. Navi Mumbai. Maharashtra. INDIA. \\ 1agshaligram@mes.ac.in \\ ameymarathe@mes.ac.in
}

\begin{abstract}
This paper explains how different subjects in a B.E. Mechanical and Automobile Engineering curriculum are covered in single industrial product(s). As students learn various subjects during their 4-year Course, it becomes difficult for them to appreciate application of principles and theory of diverse subjects on a common platform. While the Final Year project does give a good opportunity to the students to understand the different subjects in one attempt, many a times it does not achieve the purpose fully. The product(s) chosen for the illustration are a Water Chiller which is used commonly in Central Air Conditioning Plants and an automobile itself. It is hoped that students will get a feel of vast scope of Mechanical as well as Automobile Engineering after reading this paper.
\end{abstract}

Keywords: Mechanical Automobile Engineering curriculum, industrial product, Water Chiller, Automobile

\section{${ }^{1}$ Avinash Shaligram}

${ }^{1}$ Department of Mechanical and Automobile Engineering Pillai Institute of Information Technology, Engineering, Media Studies and Research,

Dr K M Vasudevan Pillai Campus, Sector 16, New Panvel - 410 206. Navi Mumbai. Maharashtra. INDIA. agshaligram@mes.ac.in
}

\section{Introduction}

The curriculum of Bachelor's degree in Mechanical and Automobile Engineering of University of Mumbai [1, 2, 3, $4,5]$ is designed in such a way that students are exposed to all the sub-areas within the broad field. This is apart from basic subjects during the First Year such as Applied Physics, Engineering Mechanics, Applied Chemistry, Engineering Drawing, C++ Programming, Engineering Mathematics, etc.; which are in any case common to all the Branches. From the $2^{\text {nd }}$ Year onwards, we have subjects which are quite diverse in their breadth. While the design of curriculum is fine especially considering time limitation of 4 years (particularly 6 Semesters from $2^{\text {nd }}$ Year onwards), the fact remains that the subjects are taught and learnt by students in isolation. In the real, industrial world there is rarely any product or process which is solely covering only one subject area. This paper attempts to illustrate application of different subjects through a single industrial product; both in the Mechanical Engineering and Automobile Engineering field.

\section{Mechanical Engineering Product}

Primarily the curriculum of Mechanical Engineering covers the 3 specializations viz.
1. Thermal Engineering
2. Design
3. Manufacturing

A linking of almost all the subjects under the Curriculum can be found in a product used in the Air Conditioning and Refrigeration field viz Water Cooled Screw Chiller.

This is used to provide chilled water for a Central Air Conditioning system. Chilled water is circulated in AHU's (Air handling Units) which consist of chilled water coil, blower section, filter section etc. The conditioned air 
is supplied from the AHU via ducting system through terminal diffusers and grilles. In this system the refrigeration unit is the Water Chiller. Depending upon the type of compressor used, the Chillers are classified as:

a. Centrifugal Chillers

b. Positive Displacement Chillers.

The positive displacement chillers are further classified into: $\begin{array}{ll}\text { i. } & \text { Reciprocating Chillers } \\ \text { ii. } & \text { Scroll Chillers } \\ \text { iii. } & \text { Screw Chillers }\end{array}$

In this paper an illustration of a Screw Chiller is used to explain how almost all the Undergraduate subjects are covered in a single product which happens to be one of the more recent and technology based product in the Air Conditioning and Refrigeration industry.

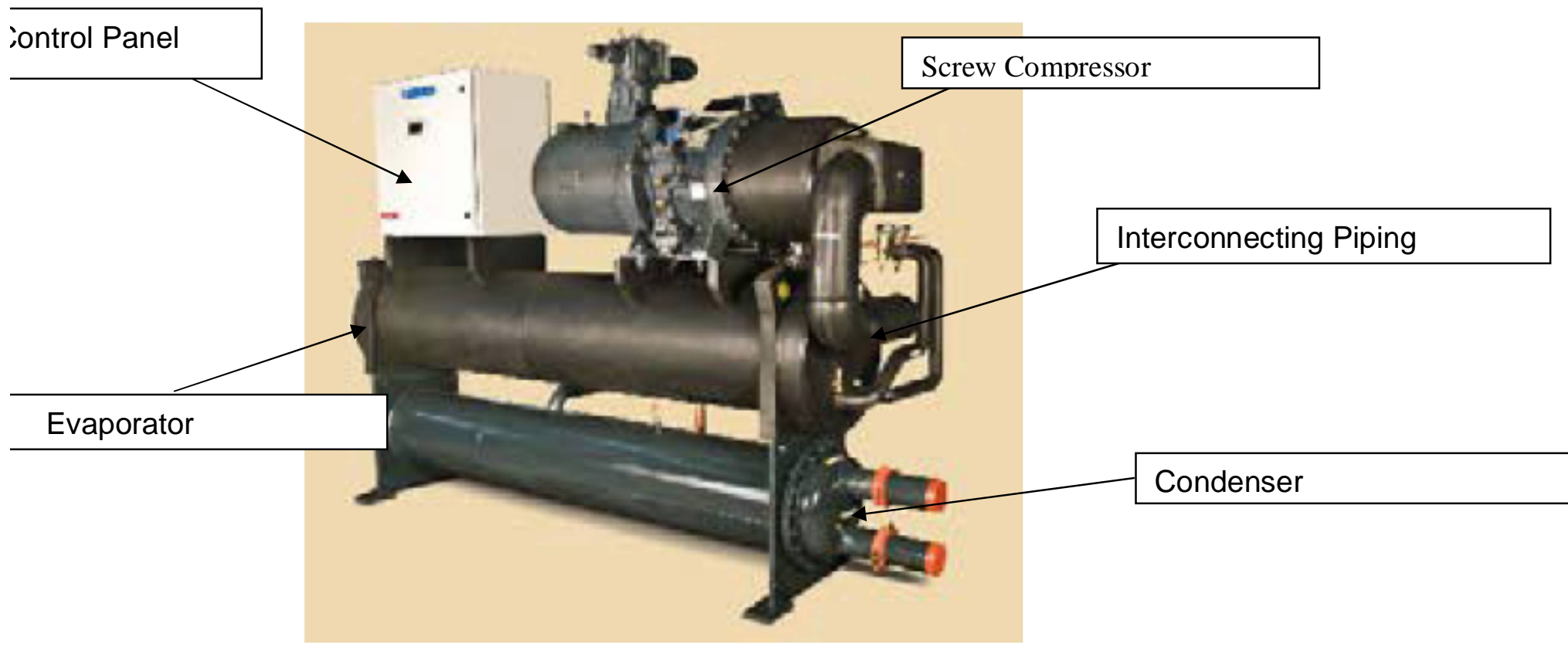

Fig 1: Water Cooled Screw Chiller [6]

\subsection{Water Cooled Screw Chiller}

As can be seen from Fig 1, the product is an assembly of 4 components viz Compressor, Condenser, Evaporator and a Control panel. In addition the 3 main components are interconnected by piping. As the Unit is meant to provide chilled water for central air conditioning plants, it follows that the design of the product mainly covers the following Thermal Engineering subjects viz

\section{$\checkmark \quad$ Heat Transfer \\ $\checkmark \quad$ Refrigeration and Air Conditioning \\ $\checkmark$ Fluid Mechanics}

The heat exchangers are designed with the basic principles of heat transfer such as 'U' value, LMTD, etc. Similarly a major consideration is required to be given to pressure drop of the working fluid (refrigerant) as it flows through the components. Of course, RAC forms the heart of the product since it is pertaining to the application of VCC (Vapour Compression Cycle). Simple but important things like type and thickness of insulation material on the evaporator shell as well as suction piping have to be decided by the product design engineer before it goes for manufacturing.

Technology plays a crucial role in such products. The heart of the Unit is the Compressor which is of semi hermetic Screw type. The key factor in today's world is the energy efficiency since it affects both; the cash outflow for the user and an indirect impact on the phenomenon of global warming. Thus use of right type of compressor results into saving in energy consumption. Compressor design and manufacture is in itself a specialized field and in fact covers possibly all the subjects such as Machine Design, Material Technology, Strength of Materials, Production Processes; etc. Since drawing is considered to be the language of Engineers, all the components (whether of the Compressor or Heat Exchangers) are manufactured and assembled only after drawings are made for each of the components. Industry follows CAD systems; particularly 3-D Solid Modelling for design of all the components. Extensive use is also made of CAE software; especially for design of heat exchangers.

The compressor motor is within the compressor housing; since it is a hermetic type compressor. Thus BEE (Basic Electrical and Electronics) is covered in design of the motor. In fact substantial application of electrical engineering principles is necessary in the design of the complete product itself. Thus there is wiring between the Control Panel and compressor motor terminals. Also motor starter (either Star Delta or Part Winding) is part of the Control Panel. You will also find extensive applications of MEM (Mechanical Engineering Measurements) since 
there is a large number of measuring and control instruments in the product. For example, pressure transducers are used to measure suction, oil and discharge pressures. Similarly thermistors are mounted on the heat exchanger inlet and outlet connections to measure water temperatures. There are also current transducers to measure the current drawn by the compressor motor. Since these compressors are uni-directional by design, a Phase Sequence Protector is used to prevent the compressor in rotating in reverse direction as it can cause damage to the rotating parts (screws) of the Compressor.

While Compressor is the heart of the system, the Controller is the brain since it decides the sequence and operation of the compressor in accordance with load. Controller (typically PLC) is an excellent example of application of Mechatronics. On the front door of the Control Panel you can see the GUI through which the operator gives the commands to the Controller. It also displays system parameters such as temperatures, pressures, etc. Also there is an extensive use of safety interlocks which ensure safe operation of the Compressor. Control logic is programmed in the Controller. Recent technology developments also involve web-interfacing of the Control system. This means you can control the Chiller which is working in Delhi by sitting in your Office in Mumbai! It is also possible to get SMS alerts of any particular event (such as Overload tripping) on your Mobile phone. All of these features point to extensive use of Electronics in industrial products.

Even a specialized subject such as Vibrations finds application in this product. Since compressor is a dynamic part, it is a source of vibration. These vibrations; if not isolated; can damage the pipe joints and lead to leakage of gas. This will result into loss of cooling. Hence design and selection of vibration isolators (such as rubber pads) is important to ensure safe and continuous running of the machine.

Finally, subjects such as MPC (Manufacturing Planning and Control) and IEERP (Industrial Engineering and Enterprise Resource Planning) ; although not directly linked to this product as such are important since manufacturing of such Chillers in a factory involves Planning, Procurement, Scheduling, Industrial Engineering ,Manpower (such as Workmen) deployment; etc.

\section{Automobile Engineering Product}

The Automobile Curriculum consists of specialized subjects related to Automobile like
$\checkmark$ Automotive Systems
$\checkmark$ Automotive Design
$\checkmark \quad$ Chassis and Body Engineering
$\checkmark$ Autotronics
$\checkmark$ Product Design and Development
$\checkmark \quad$ Vehicle Maintenance and Dynamics

The Product selected for describing curriculum is a Automobile itself. An Automobile is a combined work of different systems working together in tandem. Each system, primarily independent is influenced by effect of other systems interacting with it. Various important systems that are present in an Automobile are

- Power Plant

- Drive Train/Transmission

- Suspension

- Braking

- Electrical

- Steering

Automobile must produce its own power sufficient enough to start and maintain propulsion. In most of cases it is Internal Combustion Engines which converts chemical energy of fuel into mechanical energy. The power plant can be of mainly two types depending upon fuel supplied viz Petrol and Diesel and recently it we have seen various other types such as Fuel Cell, Hybrid and Electric. The operation is based on two basic cycles studied in Subject of Thermodynamics (Otto \& Diesel).Heat transfer also plays a important part as Energy is lost due to conduction and convection in an I.C Engine.

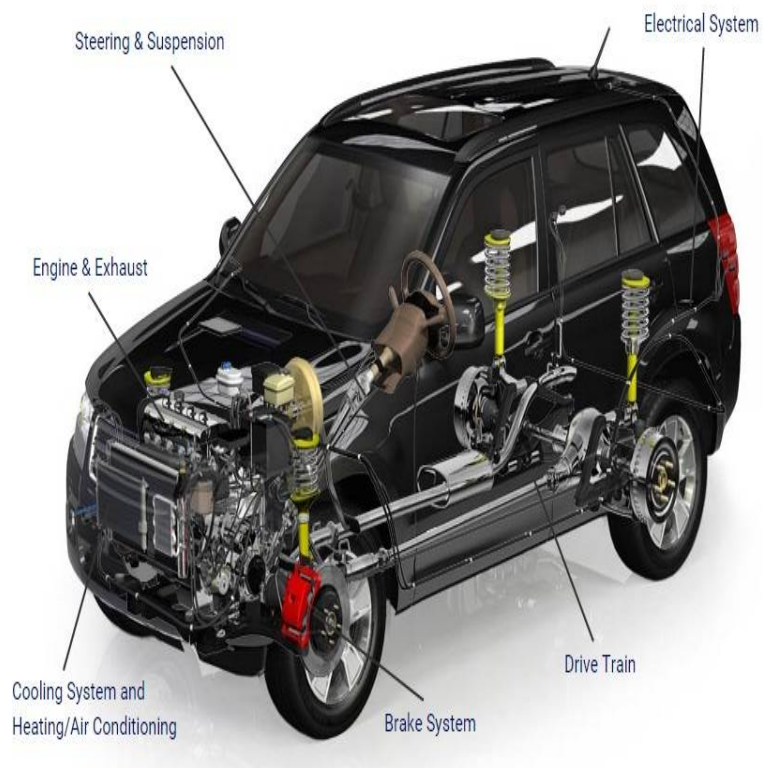

Fig 2 Various Systems in Automobile [7]

Power produced by the engine is transferred to wheels with the help of Drive train which consist of different set of linkages between Engine and Wheels. It includes Clutch, Gearbox, Universal Joints, drive shafts and differential arrangement. Subject like Theory of Machines helps student understand working of above parts in detail with its types.

Suspension system provide vehicle with a smooth ride when it encounters a rough terrain. It is achieved by damping out the vibrations which are transferred to chassis through wheels. Knowledge of subject like Mechanical Vibrations at this point will help student better understand 
the system. Suspension system enhances life of all components mounted on chassis like engine, transmission etc by providing smoother working conditions.

Braking system absorbs the kinetic energy and stores it in some other form (heat or electricity).In Modern Automobile; Electrical system is divided into various subsystems like Battery, Charging, Starting, Ignition, Lighting and Instrumentation etc along with Electronic Control Unit and use of Sensors and Actuators. All the basic principles studied in various subjects of First Year like Applied Chemistry, Physics and BEE first year are applied here. For example Battery works on principle of electrochemistry. Alternator or charging system works on principle of Electromagnetic Induction etc.

There is also application of subject like Industrial Electronics in Alternator where a 4 Diode Bridge rectifier is used for Rectification of AC to DC current. Also 8085 and 8051 Microprocessor is still used in Automobiles for transmitting data. A protocol named CAN is used in majority of vehicles for communication with ECU.

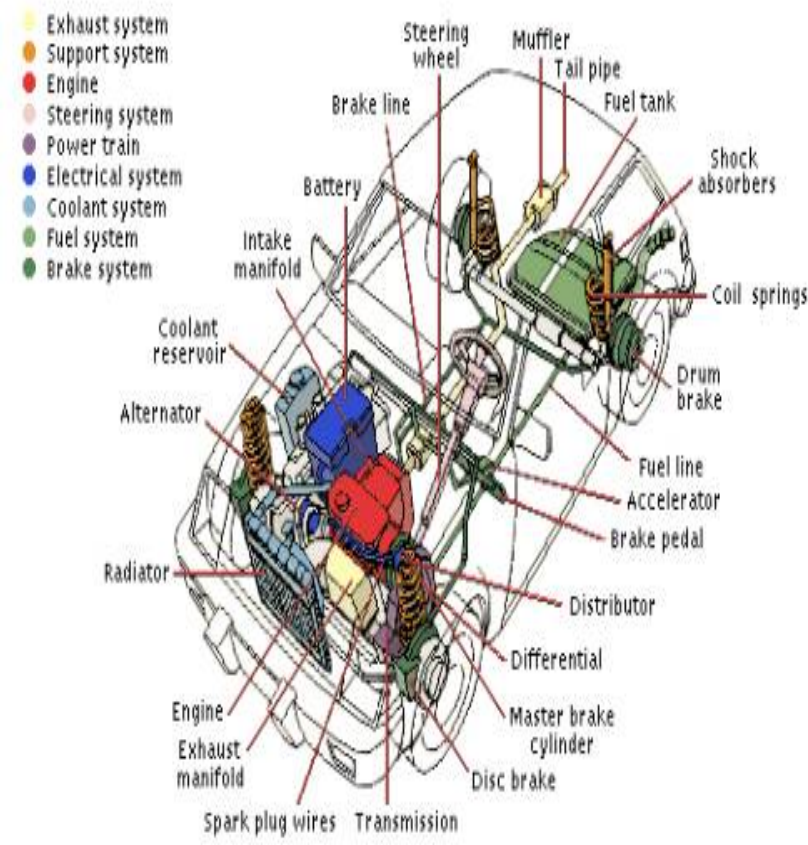

Fig.3 FEFWD Automobile [8]

The type of Clutch, Gearbox, Drive (FEFWD/FERWD/RERWD/REFWD etc.), types of Wheel, Braking system and suspension system are covered in Automotive System. Design of all above component is covered in Automotive Design. Various types of Structure layouts such as Open ,Closed ,Semi Integral,Monocoque etc along with Calculation of Loading cases along with Vehicle Weight distribution with some concepts from Strength of Materials (SFD \& BMD) are covered in Chassis and Body Engineering. All the Electrical Systems and sub-systems are covered in Autotronics along with Lighting systems and Wiring Harness System $(\mathrm{H} \& \mathrm{E}$ type) .Continuous working of all the above systems and subsystems are possible if they are undergoing proper Maintenance schedule which is covered under Vehicle Maintenance. Selection of Material for Automobile Body also plays a critical part in Overall Weight Distribution. Hence knowledge acquired in Material Science also plays a crucial role.

Apart from these various Subjects like Operation research and Product Design and Development are helpful for understanding fundamentals of Optimization techniques and product design concepts in industries. Automobile Industry follows $\boldsymbol{C A D}$ systems particularly 3D Modelling of all the systems and subsystems. Extensive use of CAE software is also made especially for Design of Chassis.

\section{Conclusion}

As can be seen from the examples cited in this article, virtually all the subjects in the curriculum of Mechanical and Automobile Engineering need to be used while designing and manufacturing of an industrial product. It is important that students learn and understand the basic principles of each of the subjects so that when they join industry they will find it easier to apply those principles in whichever product/field that they will go into.

It is a fact that the students get an opportunity to see this linkage only after they graduate and join the industry; which may be a bit late. Hence it is suggested that if there is a common central facility (it may be on a Citybasis or University-basis) in which such live industrial products/systems are maintained then it can be a very good experience for the students to see these products. However it is important and necessary that these products are made operational so as to make it a truly learning experience for the students and faculty alike.

\section{Acknowledgements}

The authors would like to thank Management of the Institute for the support given during the course of this work. Particularly we would like to thank Dr K M Vasudevan Pillai, Founder, Chairman and CEO of Mahatma Education Society ; and Dr R I K Moorthy, Principal, Pillai Institute of Information Technology, Engineering, Media Studies \& Research, New Panvel.

\section{References:}

1) University of Mumbai First Year Engineering Curriculum

http://archive.mu.ac.in/syllabus/4.76\%20F.\%20E.\%20Sem. \%20I\%20\&\%20II.pdf

2) University of Mumbai Second Year Mechanical Engineering Curriculum

http://archive.mu.ac.in/syllabus/4.80\%20S.E\%20Mechanic al\%20Engineering.pdf

3) University of Mumbai Second Year Automobile Engineering Curriculum http://archive.mu.ac.in/syllabus/4.69\%20S.E.\%20Automobi le\%20Engineering.pdf 
4) University of Mumbai Third \& Final Year Mechanical Engineering Curriculum http://archive.mu.ac.in/syllabus/4.32\%20\&\%204.33\%20TE $\% 20 \& \% 20 \mathrm{BE} \% 20-\% 20 \mathrm{Mech} \% 20 \mathrm{Engg.pdf}$

5) University of Mumbai Third \& Final Year Automobile Engineering Curriculum http://archive.mu.ac.in/syllabus/4.19\%20\&\%204.20\%20TE \%20\&\%20BE\%20-\%20\%20Automobile\%20Engg.pdf

6) Water Cooled Screw Chillers product brochure, Blue Star Limited. www.bluestarindia.com Last accessed on $30 / 09 / 2015$ at 16.36 p.m.

7) https://sengerandu.wordpress.com/tutorials/automobileengineering/various-systems-of-an-automobile/ Last Accessed on 30/09/2015 at 15.21 p.m

8) http://warrantycompete.com/systems.asp. Last Accessed on $30 / 09 / 2015$ at 15.21 p.m 